\title{
SOCIALIZAÇÃO E COMUNICAÇÃO POR MEIO DE REGRAS: ADULTOS E CRIANÇAS EM RELAÇÃO, NO CONTEXTO DE UMA CRECHE EM SANTOS - SP
}

\author{
Simone Carvalho de Oliveira ${ }^{\text {DD } 1}$ e Eunice Nakamura (iD)2
}

\section{Resumo}

Este artigo apresenta parte da pesquisa de doutorado realizada em uma unidade de Educação Infantil em Santos - SP, uma creche conveniada com a Secretaria de Educação de Santos, baseada no método etnográfico e cujo objetivo foi compreender o processo de comunicação entre adultos e crianças por meio de regras. Foram observadas e acompanhadas, entre março e dezembro de 2018, situações do cotidiano de 15 crianças (entre três e quatro anos) de uma sala do Maternal II em interação com a professora responsável. O artigo centrou-se na análise do processo de socialização, de como os adultos moldam o comportamento e as formas de comunicação das crianças por meio de regras, assim como as concordâncias e transgressão das crianças durante esse processo. Ao privilegiar a perspectiva das crianças foi possível acessar outras dimensões sobre a socialização e a comunicação por meio das regras, destacando-se possibilidades de relações menos assimétricas que podem emergir entre adultos e crianças. O estudo aponta a necessidade de reconhecimento da atuação das crianças e da sua maneira peculiar de vivenciar a cultura, onde ela aprende e também ensina, transforma-se na interação com os adultos e seus pares, mas também é agente de transformação.

Palavras-chave: Criança; Comunicação; Socialização; Etnografia; Educação Infantil.

\section{SOCIALIZATION AND COMMUNICATION THROUGH RULES: ADULTS AND CHILDREN IN RELATION IN THE CONTEXT OF A DAYCARE CENTER IN SANTOS - SP}

\section{Abstract}

This article presents part of the doctoral research carried out in a Children's Education unit in Santos - SP, a daycare center under contract with the Santos Education Department, based on the ethnographic method and whose objective was to understand the communication process between adults and children by means of rules. Daily situations of 15 children (aged between three and four years old) from a kindergarten II room in interaction with the teacher in charge were observed and monitored between March and December 2018. The article

\footnotetext{
${ }^{1}$ Doutoranda em Ciências da Saúde pela Universidade Federal de São Paulo. E-mail: simooliveira@hotmail.com

${ }^{2}$ Doutora em Antropologia Social e professora do Departamento Políticas Públicas e Saúde Coletiva da Universidade Federal de São Paulo. E-mail: e.nakamura@unifesp.br
} 
focused on the analysis of the socialization process, how adults shape the children's behaviour and forms of communication through rules, as well as the children's agreement and transgression during this process. By privileging the children's perspective, it was possible to access other dimensions about socialization and communication through rules, highlighting possibilities for less asymmetrical relationships that may emerge between adults and children. The study points out the need to recognize the role of children and their peculiar way of experiencing culture, where they learn and also teach, transform themselves in the interaction with adults and their peers, but are also agents of transformation.

Keywords: Child; Communication; Socialization; Ethnography; Child education.

\section{Introdução}

Este artigo apresenta parte da pesquisa de doutorado que teve como objetivo compreender e analisar o processo de comunicação entre adultos e crianças por meio de regras. A partir de dados da pesquisa etnográfica realizada em uma creche de pequeno porte, em Santos - SP, o artigo centrou-se na compreensão de como os adultos moldam o comportamento e as formas de comunicação das crianças por meio de regras, assim como as concordâncias e transgressões das crianças durante esse processo.

A creche pesquisada possui convênio com a Secretaria de Educação de Santos desde a década de 1990, atendendo crianças divididas entre os berçários (até dois anos de idade), as salas de Maternal I (de dois a três anos) e Maternal II (de três a quatro anos).

As observações foram realizadas durante dez meses, entre março e dezembro de 2018, com 15 crianças (entre três e quatro anos) de uma sala do Maternal II e a professora responsável.

A pesquisa baseou-se na etnografia com crianças (COHN, 2005; 2019; PIRES, 2007; 2008; 2010; JAMES; PROUT, 2015), considerando-as como sujeitos sociais. Observando suas próprias formas de se comunicar e de se relacionar com o mundo foi possível apreender suas ideias e concepções, compreender como os adultos modelam o comportamento das crianças e como elas participam ativamente desse processo. Segundo Marchi (2018, p. 729), dar voz às crianças não significa conceder-lhes algo, mas ouvi-las diretamente, considerando o que as crianças têm a dizer sobre elas, suas realidades e "reconhecer a existência de diferentes vozes presentes no campo da pesquisa".

A análise fundamentou-se em dados relativos às observações e ao acompanhamento de situações do cotidiano dessas 15 crianças, envolvendo a relação entre elas e com a professora.

Espera-se que o artigo possa contribuir para estudos que buscam pensar as crianças a partir delas mesmas e o seu papel no processo de socialização no contexto educacional. 


\section{Crianças, infâncias e a socialização: referencial teórico}

Criança e infância são conceitos distintos, pois a criança, enquanto ser biológico, sempre existiu em qualquer sociedade, enquanto a noção da infância foi concebida na modernidade, segundo Ariès (1981). O historiador francês nos apresenta o sentimento de infância: a paparicação, a preocupação com a moral, a disciplina e o papel da família e da escola irão definir a infância, distinguindo assim os adultos das crianças com particularidades geracionais específicas. 0 estudo de Ariès (1981) nos mostra que a noção de infância foi concebida na Europa ao longo da história ocidental, alinhada às mudanças históricas na sociedade (COHN, 2005; SARMENTO, 2008).

De acordo com Sarmento (2008), no mundo ocidental, antes da Era Moderna, as crianças não tinham estatuto próprio e assim que adquirissem as mínimas condições físicas para participar das atividades sociais eram incorporadas precocemente ao universo dos adultos. Somente no século XVII a criança deixou de ser invisibilizada em sua condição particular, não mais considerada como um adulto em miniatura.

Embora de importância inquestionável, por colocar a temática em pauta no campo epistemológico, o trabalho de Ariès (1981) foi posteriormente criticado por não conceber a noção da infância fora da modernidade do mundo ocidental. Como explica Cohn (2014, p. 22), criança e infância podem ser pensadas de várias maneiras, dependendo do contexto histórico cultural, e "a ideia de infância pode não existir, ou ser formulada de outros modos".

No campo da Sociologia, a temática infantil foi abordada inicialmente nos estudos de Émile Durkheim (2016), a partir do conceito de socialização. Nesse processo, a criança era concebida como um ser passivo na relação com o adulto, em instituições como a família e a escola, para enfim poder ser inserida na sociedade. A socialização era vista como a incorporação do papel social do indivíduo e, referenciada por esse sociólogo, como sinônimo de educação.

Nessa perspectiva, a socialização é descrita como um processo sem relação de reciprocidade. A criança é considerada um ser imaturo e incompleto que irá adquirir passivamente os valores e as regras sociais por meio da educação por adultos.

De acordo com Sarmento (2008), a educação das crianças na sociedade, seja na família ou na escola, era e ainda é baseada na visão do adulto, numa relação desigual. O autor ressalta que a construção moderna da infância está relacionada à institucionalização das crianças, com o advento das creches e escolas públicas. O papel da escola na redefinição da infância ainda permanece em destaque, porém, segundo ele, a construção da infância e a separação do mundo dos adultos devem-se a questões históricas e simbólicas sobre o universo infantil.

A ideia padronizada da infância, desmembrada do contexto social, também é criticada por Prout (2011), uma vez que o modelo europeu não contemplava a noção de infância nos países menos desenvolvidos. A Sociologia 
moderna, segundo o autor, não abarcava a complexidade das mudanças sociais e, é nesse contexto, que nasce a Sociologia da Infância.

Essa área da Sociologia percorreu um longo caminho, sendo hoje considerada um campo epistemológico de destaque, pela relevância da categoria social geracional na contemporaneidade. É uma importante área do saber para se compreender o processo de socialização da criança e reconhecer o seu papel não só na reprodução, mas produção e transformação de cultura. A alteridade da criança é admitida, desconstruindo o conceito de socialização arraigado pelo pensamento de Durkheim (SARMENTO, 2005).

De acordo com Cohn (2005) e Pires (2008), tanto a Sociologia como a Antropologia fortaleceram a ideia de que as crianças não são sujeitos inacabados, a serviço do treinamento dos adultos, mas atuam com competência, e à sua maneira, em suas realidades.

No campo da Antropologia, o papel social da criança também tem sido revisto, à medida que os conceitos de cultura e sociedade vão sendo questionados.

A cultura é dinâmica, está em movimento, em transformação, um processo do qual a criança participa ativamente. Tomando a cultura como um sistema simbólico compartilhado (GEERTZ, 1989), Cohn (2014, p. 33) afirma que a concepção de criança como um ser incompleto deve ser revista, pois ela atua no presente, dando sentido a sua realidade, "portanto, a diferença entre as crianças e os adultos não é quantitativa, mas qualitativa; a criança não sabe menos, sabe outra coisa".

A Antropologia da Criança surge dessa reflexão sobre as concepções de cultura e de socialização, questionando o papel passivo dado à criança, afirmando a sua participação na produção da cultura.

James e Prout (2015) também destacam a concepção da infância como uma construção social, que deve ser contextualizada, contrapondo-se a um conceito universal de infância. Os autores apresentam o conceito de "agência" (agency), que permite pensar a criança como protagonista da sua própria história, podendo ser estudada por ela mesma, reconhecendo sua condição de ator social, com papel ativo na produção de cultura e nas relações sociais. Nesse sentido, a partir do conceito de "agência" é possível afirmar que crianças são capazes de atribuir significados e atuar na sociedade de modo eficiente e particular, reproduzindo, mas também transformando a cultura (COHN, 2014; JAMES; PROUT, 2015; PIRES, 2008; SARMENTO, 2008).

Sendo assim, os estudos na Antropologia e na Sociologia redefinem os conceitos de criança e infância, levando à realização de pesquisas com a participação direta das crianças na produção dos dados. A criança, não mais considerada passiva e dependente, mostra-se atuante ao vivenciar sua cultura por meio das interações, não se adequando à noção tradicional de socialização. Os novos estudos da infância passam a abordar a complexidade do tema por meio da interdisciplinaridade entre as várias áreas das ciências sociais e humanas (MÜLLER; NASCIMENTO, 2014). 
Essas novas perspectivas e concepções contribuíram para problematizar, neste artigo, o processo de socialização das crianças nas instituições escolares, trazendo à tona questões sobre como as crianças e adultos interagem na cultura.

\section{Metodologia}

A pesquisa adotou a abordagem etnográfica com o objetivo de se compreender os significados dados pelas crianças à sua realidade, no contexto da Educação Infantil. As informações foram registradas em diário de campo, realizando-se uma "descrição densa" dos contextos observados (GEERTZ, 1989).

A escolha pelo método etnográfico deveu-se à possibilidade de estudar e entender as crianças, observando-as em suas rotinas, interações, ouvindo-as sobre o que e como elas têm a dizer. Nesse sentido, a pesquisadora pôde se relacionar e compartilhar experiências diretamente com as crianças, por meio da observação participante, considerando-as sujeitos legítimos do estudo ao ouvir suas concepções acerca da realidade (COHN, 2005).

O contexto identificado para a pesquisa foi uma creche de pequeno porte, no município de Santos - SP, conveniada com a Secretaria Municipal de Educação desde a década de 1990. Foram observadas e ouvidas 15 crianças na faixa etária de três a quatro anos de idade, que estavam em uma sala do Maternal II, e o adulto responsável pela classe. A faixa etária foi escolhida em comum acordo com a diretora e a professora desse grupo de 15 crianças.

As observações foram realizadas durante dez meses, entre março e dezembro de 2018, buscando apreender as formas com que as crianças se comunicam e se relacionam entre si e com a professora.

As crianças frequentavam a creche em período integral, com início às $7: 30 \mathrm{~h}$ e término às $16: 30 \mathrm{~h}$. A pesquisadora acompanhou a rotina das crianças, desde a entrada pela manhã até o final da tarde, o modo como eram recebidas no portão de entrada, o percurso até a sala de aula, os momentos das refeições, as atividades realizadas durante as aulas, nos momentos lúdicos e até durante o descanso. Para análise dos dados apresentados neste artigo, a pesquisadora optou por selecionar alguns episódios observados e vivenciados pelas crianças.

O estudo foi submetido e aprovado pelo Comitê de Ética em Pesquisa da Universidade Federal de São Paulo e, a fim de garantir o sigilo e o anonimato do contexto da pesquisa, utilizou-se nomes fictícios para as 15 crianças e para a professora, que participaram do estudo.

\section{As regras na rotina da creche: cobradas, incorporadas e lembradas por meio de "palavras mágicas"}

Desde o início das visitas exploratórias foi possível identificar e conhecer as regras presentes na rotina do Maternal II por meio da interação das crianças com a professora e entre elas. 
A pesquisadora interagiu em todas as visitas com as crianças e a professora. Fizeram parte de sua rede de relações e de acompanhamento durante a pesquisa: a professora Cida e quinze crianças: Samuel, Marcelo, Isabela, Yuri, Joaquim, Rafael José, Juliana, Rafael, Pedro, Felipe, Manuela, Maria Paula, Luana, Mauro e Gabriel.

À medida que a presença da pesquisadora na instituição foi gradativamente tornando-se uma constante, foi possível apreender e conhecer melhor as regras que faziam parte do cotidiano das crianças, assim como identificar novas, menos frequentes.

A rotina das crianças era moldada por regras repetidas exaustivamente pelo adulto, compartilhada pelas crianças entre si, e esperava-se que fossem incorporadas por quem se integrasse ao grupo, como a pesquisadora. Escovar os dentes, como comer, o que fazer quando sobrava água na caneca foram algumas regras percebidas em diferentes situações observadas e vividas. Algumas delas, como no momento das refeições, só foram compreendidas pela pesquisadora pelo fato de estar com as crianças.

Um dia, na hora do almoço, uma das crianças chamou a atenção: "Ô tia, ele não tá fazendo cabeça de tartaruga!". Cida me explicou que pedia para que as crianças colocassem a cabeça mais à frente do corpo, perto do prato, para não cair comida no chão e não sujar a roupa delas também, "como a cabeça de uma tartaruga". Outras regras conhecidas, como "tem que comer toda a comida que está no prato", eram frequentemente utilizadas pelo adulto. Essa regra, assim como o tempo delimitado para as refeições, se sobrepunha à importância de as crianças usarem os talheres sozinhas. Portanto, se no final do almoço ou jantar ainda houvesse comida no prato o adulto auxiliava a criança, dando-lhe a comida na boca.

As orientações quanto ao modo das crianças se comportarem e se comunicarem eram lembradas frequentemente pelo adulto por meio da fala, gestos, movimentos ou por cartazes afixados em alguns espaços da sala. A professora repetia diariamente com as crianças, nesse contexto de regras compartilhadas e reafirmadas, o que eram chamadas de "palavras mágicas": "por favor", "obrigado", "com licença" e "desculpe". Todas elas estavam escritas nessa ordem e ilustradas num cartaz preso à parede da classe. No entanto, a pesquisadora tinha dúvidas se essas regras faziam sentido para as crianças, como ficou evidente quando Samuel disse, num certo dia, para Cida: "Você não precisa falar toda hora isso: obrigado...".

Em outro cartaz estavam escritas algumas atitudes que eram estimuladas, tendo ao lado de cada uma delas o sinal de positivo, e outras que eram inibidas, ressaltadas com o sinal do polegar para baixo, indicando algo negativo. O cartaz foi confeccionado com uma cartolina azul e tinha o título de "COMBINADOS", aludindo provavelmente ao fato de que as regras foram acordadas com as crianças. Logo abaixo aparecia o subtítulo: "PODE FAZER", sendo elencadas algumas ações: brincar, abraçar, emprestar o brinquedo, ajudar a professora, respeitar a professora e amigos, organizar os brinquedos, utilizar as "palavras mágicas". Após essa seção aparecia em destaque outro subtítulo: "NÃO PODE 
FAZER", descrevendo uma lista de comportamentos proibidos: bater nos amigos, empurrar, beliscar, correr na sala, gritar e falar alto, tirar o brinquedo do amigo, jogar o brinquedo.

Dependendo do comportamento das crianças, a professora estimulava os colegas a responderem se aquele comportamento era positivo ou negativo. Quando o comportamento era considerado reprovável, além do sinal (o dedo polegar voltado para baixo), as crianças verbalizavam "fom fom", para reforçar que aquele comportamento não era aceito.

Várias regras também orientavam o comportamento das crianças durante as refeições: "tem que rezar antes de comer", "não pode conversar", "tem que comer tudo", "tem que raspar o prato", "só vai comer a sobremesa quem comer toda a comida", "quem não comer não brinca", sendo lembradas e cobradas tanto pelo adulto como pelas próprias crianças. Diariamente, a comida vinha da copa trazida por uma funcionária que pouco interagia com as crianças. Os pratos prontos e talheres eram colocados à frente de cada criança. Normalmente elas tinham liberdade de escolher o lugar para sentar, mas a professora podia mudálas de lugar, caso insistisse em interagir com a criança ao lado. A comunicação no momento das refeições não era, portanto, estimulada, embora frequentemente as crianças se comunicassem com entusiasmo, mesmo quando interrompidas pela professora Cida: "Não vou falar mais! Agora é pra comer! "

Assim como durante as refeições, quando um adulto estava dirigindo alguma atividade, a comunicação entre as crianças normalmente era inibida. Foi observado várias vezes a professora mudar alguma criança de lugar por estar conversando, "cutucando", rindo ou brincando com o colega do lado, sem necessariamente estar havendo conflito entre as crianças.

As restrições do adulto às formas de comunicação entre crianças foram observadas em outras situações pelo uso da interjeição "shhh", para impor silêncio. As crianças pareciam entender que esse som prolongado significava uma ordem para fazer silêncio. Às vezes o som era acompanhado com o indicador da mão direita, na vertical, sobre os lábios, seguido da palavra "silêncio" ou "psiu". No horário do almoço, como mencionado, a conversa não era estimulada e a professora verbalizava uma mensagem lembrando a regra ou só utilizava o recurso do "shhh".

Por outro lado, as crianças eram bastante estimuladas a se expressarem, mas isso ocorria, na maioria das vezes, em atividades dirigidas e com a orientação de que falassem uma por vez. Nas rodas de conversa isso era bastante pontuado: "Tem que esperar o amigo terminar de falar", "Agora é a vez do amigo". Essa regra era lembrada pelas próprias crianças. Numa ocasião, Pedro falou: "Meu pai gostou do presente! ", "Do dia dos pais" (havia sido o dia dos pais e as crianças prepararam uma lembrancinha na escola, um portaretratos, com as fotos que trouxeram), outros começaram a falar ao mesmo tempo sobre esse dia e Rafael lembrou aos colegas: "Um de cada vez!".

Observou-se, no entanto, várias situações em que as crianças se expressavam ao mesmo tempo, sem a mediação do adulto. Elas pareciam não 
se incomodar, como os adultos, quando falavam ao mesmo tempo e, também, não pareciam se constranger frente a longos silêncios durante a interlocução.

A movimentação das crianças pelos espaços fora da classe também era pautada por meio das regras: andar em fila pelo corredor, não correr, não gritar e seguir as instruções do adulto de quando retornar à classe ou em qual pátio podiam brincar.

Sendo lembradas diariamente, em várias situações, as regras eram incorporadas e reproduzidas pelas crianças em sua relação com as outras crianças e também com os adultos, como a pesquisadora: "Tia, tem que jogar no ralinho", me orientou Marcelo sobre o restante da água que sobrou no copo. Aí percebi que havia um ralo no corredor, quase à entrada da porta da sala, e fiz o que ele me "ensinou". Marcelo não falou mais nada, mas pareceu satisfeito com a minha atitude (Diário de campo, ago. 2018).

As regras eram, assim, observadas, compartilhadas e reproduzidas nas interações entre adultos e crianças e entre as próprias crianças na rotina da creche, parecendo que as crianças expressavam certa concordância com as regras, principalmente quando as reproduziam em suas relações.

Essas regras pareciam evidenciar uma tendência à homogeneização e padronização das crianças no que se refere ao comportamento estimulado, esperado e cobrado delas. As crianças tinham pouca liberdade e eram cobradas o tempo todo. Para o adulto a questão do limite dado às crianças parecia inquestionável e importante para não comprometer sua educação, remetendo à ideia de socialização de Durkheim (2016), na qual o autor ressalta a ação unilateral do adulto sobre criança, ou seja, ela deve submeter-se passivamente a sua autoridade para ser inserida na sociedade e tornar-se um ser social. Por meio das regras e das disciplinas institucionais a criança é moldada para tornarse um adulto exemplar naquela cultura.

A internalização das regras e a utilização de formas verbais evidenciaram as tentativas de comunicação do adulto com as crianças, principalmente por meio de sinais, como "fom fom", assim como pelas "palavras mágicas" lembradas em várias situações, inclusive pelas crianças:

Um dia no pátio, Samuel deu uma "gravata" em Joaquim. Eu vejo. Num impulso estendi a mão para os dois. Joaquim começou a chorar. A professora falou para os dois sentarem no banco comigo para se acalmaram. Joaquim permaneceu chorando. Samuel me explicou que bateu em Joaquim porque ele o chamou de lagartixa. O pescoço de Joaquim estava vermelho. Os dois ficam sentados do meu lado no banco. Joaquim falou, olhando para Samuel: "Pede decupa, pede decupa!". Falou repetidamente, mas não foi atendido. (DIÁRIO DE CAMPO, out. 2018).

As regras também eram passadas de maneira lúdica, com histórias e principalmente com músicas. Às vezes, quando as crianças estavam com dificuldade de acordar após a sesta da tarde, Cida cantava: "tá na hora de 
acordar, acordar...". Para incentivar as crianças a guardarem os brinquedos e irem lavar as mãos, Cida entoava outra música: "Tá na hora de guardar, de guardar, de guardar...". Na hora de escovar os dentes, a professora auxiliava algumas crianças, segurava suas cabeças e, fazendo movimentos circulares com a escova, cantava: "Bolinha, bolinha, bolinha!".

No entanto, no geral, a lembrança das regras parecia seguir um padrão disciplinar, punitivo ou de ameaça. Em algumas ocasiões, o adulto lembrava as crianças sobre as regras para evitar alguma situação de perigo, como por exemplo, quando Cida alertava para o "sapão" que havia atrás da porta do outro lado do banheiro dos fundos, para que ninguém abrisse, pois era o depósito de material de limpeza.

Seria quase impossível não relacionar essas questões com a noção de disciplina apresentada por Foucault (1986, p. 125), que expõe e analisa as relações de poder na modernidade e o controle do comportamento por meio da disciplina. Discorre sobre o controle do corpo, "o corpo que se manipula, se modela, se treina, que obedece".

A disciplina dos corpos infantis, observada durante a pesquisa, trouxe reflexões sobre o conceito foucaultiano da fabricação de "corpos dóceis". As crianças tinham seus tempos e espaços na creche mediados pelos adultos. Esse controle nas relações interpessoais foi observado de várias formas no cotidiano, e, na maioria das vezes, oculto sob a noção de cuidado do adulto para com a criança pequena.

Ressaltamos o conceito de disciplina, da perspectiva apresentada por Foucault, para refletir sobre um contexto escolar do século XXI, em que o controle do tempo e espaço também é hierarquizado. A crianças são separadas por idade, em classes distintas; as atividades são desenvolvidas por grau de dificuldade, a fim de se manter uma ordem progressiva, nivelada, herdada do século XVIII, a escola seriada (FOUCAULT, 1986).

A criança era, assim, cuidada e supervisionada por todo o período que permanecesse na creche. Para "o seu próprio bem" seus movimentos deviam ser controlados e seu tempo ocupado com atividades distribuídas pelos adultos ao longo do dia. Embora a criança pudesse pedir licença para ir ao banheiro, de acordo com a sua vontade, havia uma regra em relação à hora do "xixi", da higiene pessoal, do soninho e do parquinho, entre outras atividades controladas pelos adultos.

Em todas as salas havia uma câmera que filmava a rotina das crianças. As imagens podiam ser vistas e revistas na sala da diretoria. Além disso, todas as salas possuíam janelas para o corredor externo da creche. Notou-se que os adultos, como a diretora e outras dirigentes, olhavam para o interior das salas ao passarem pelo corredor. As regras eram, portanto, cobradas das crianças, mas também dos adultos, pelas pessoas hierarquicamente superiores na creche, marcando as relações de poder no cenário escolar. Foucault (1986, p. 156), ao discorrer sobre a vigilância hierárquica, afirma que, na sociedade moderna, para que prevalecesse a ordem e o cumprimento das regras, o "olhar disciplinador" 
em níveis hierárquicos serviu para otimizar e integrar os mecanismos de controle nas instituições.

O tempo das crianças na creche deveria ser otimizado e, na repetição da rotina, por meio de regras, os corpos das crianças eram esculpidos. Diariamente, nem sempre identificando o adulto que estava falando, a "tia" da limpeza ou a professora de outra classe, a pesquisadora ouvia: "Levanta!", "Não corre!", "Espera!", "Não grita!", "Não mexe aí!", "Vai fazer xixi!", "Eu não mandei levantar", entre muitas outras frases disciplinadoras dos corpos infantis.

\subsection{Transgressão às regras: nem sempre as crianças cumpriam as regras}

Como já mencionado, as regras eram passadas verbalmente, por escrito, desenhos, símbolos, ações, ameaças, punições e gestos, no entanto nem sempre eram observadas pelas crianças ou aceitas facilmente. As crianças que não seguiam as regras eram consideradas más, indisciplinadas ou incapazes de entendê-las. No entanto, conforme observado pela pesquisadora, elas pareciam ter assimilado as regras, mesmo que nem sempre as cumprissem.

Cohn (2014, p. 231), ao descrever sobre concepções de infâncias em cenários institucionais, nos aponta como a ideia de socialização nesses espaços está marcada por meio da disciplina dos corpos infantis. Corpos esses que deverão ser participativos, mas maleáveis e conformes à condução do professor. Nesse sentido, a autora afirma que "a escola também busca produzir certa infância, e o faz. Mas demonstra também que as crianças a isso resistem constantemente".

Se, de um lado, as regras eram sempre repetidas, de outro lado, havia transgressões às regras. As crianças andavam para lá e para cá na creche, falavam, levantavam, "cutucavam" o amigo, se mexiam, chamavam a "tia" várias vezes no dia, falavam ao mesmo tempo, falavam alto, abraçavam, corriam. O adulto, buscando manter a rotina da creche, procurava conduzir o comportamento das crianças para certo padrão normal de infância.

$\mathrm{O}$ adulto parecia recear a falta de controle das crianças. No geral, quando saíam da sala, a professora fazia antes combinados com as crianças, na maioria das vezes sem sucesso. Nessas situações, para os adultos, elas estavam quebrando regras, como ocorreu numa situação observada no final do ano letivo:

No dia da visita [de adolescentes de uma escola particular à creche], Cida reuniu todas as crianças e fez um sermão: "Eu não quero ninguém pendurado (nos adolescentes). Pode brincar, mas tá molhado o chão, pode se machucar. Não quero brincadeira de corre corre. Tudo bem? Combinado? Vamos de mãozinha dada, devagarinho." Fomos para o pátio. Os adolescentes enchiam bexigas coloridas para as crianças brincarem, faziam esculturas de balões em formato de espada, pintavam os rostos e mãos das crianças com tinta guache: bigodinho de gato no rosto, coração na 
mão. As crianças corriam, pulavam, gritavam, sorriam, brincavam [...] durante um tempo eu as observei: corriam no pátio, umas atrás das outras, com bexigas nas mãos, brincando com as bexigas redondas e cutucando com as de formatos de espadas as cabeças dos colegas [...] elas queriam movimentar-se. Ouvi a professora Cida dizer: "As crianças precisam correr!", mas entre as outras professoras a conversa era que tinha que ficar de olho, se ficassem livres, correndo, poderiam se machucar. (DIÁRIO DE CAMPO, out. 2018).

As crianças não vivenciavam a rotina e as regras na creche de maneira uniforme. Nas relações com o adulto e entre elas, os comportamentos oscilavam, dependendo da regra que estava em jogo na interação. As crianças ora transgrediam as regras, como nas situações apontadas, ora atuavam de acordo com elas, seguindo a rotina estabelecida e esperada.

O adulto, no entanto, chamava a atenção das crianças diariamente, pois elas falavam ao mesmo tempo em várias situações ou conversavam em momentos em que a regra era ficar em silêncio, como durante as refeições. Essas pareciam ser as regras às quais as crianças mais resistiam, por isso, diariamente, o adulto utilizava a interjeição "shhh", impondo silêncio. "Um de cada vez" e "espera o amigo falar", também eram frases frequentemente utilizadas pelo adulto, e igualmente, por algumas crianças. A regra de "aguardar a sua vez" era estimulada tanto na comunicação como em várias atividades.

A gênese de todas as regras da creche parecia fundamentar-se na ideia de socialização para o futuro ou, como dizia a professora Cida, para o preparo das crianças para "o mundo real". O cotidiano na classe era repleto de afirmações e projeções do adulto sobre o papel das crianças para o futuro. A professora explicava em voz alta para as crianças os motivos das regras cobradas e do conteúdo que estava sendo trabalhado. E assim, diariamente, ela justificava suas ações para as crianças e para a pesquisadora, ressaltando as regras na rotina da creche, a obediência das crianças, o desempenho nas atividades reconhecer as letras do próprio nome, nomear cores, formas, tamanhos, números.

No entanto, essas cobranças não eram feitas sem contradições e conflitos entre o que era falado e o que as crianças faziam. Enfim, contradições foram observadas entre o caráter disciplinador das regras relacionadas à socialização das crianças, necessárias para sua inserção social, e a transgressão dessas mesmas regras pela necessidade de flexibilizá-las, segundo as concepções de crianças: têm que se comunicar, têm que ficar soltas.

Ao manifestarem situações de transgressão às regras, as crianças evidenciaram a potência do conceito de "agência" (agency) na análise de seus comportamentos. De acordo com James (2014, p. 34), o conceito nos possibilita repensar não apenas a noção de infância, mas as maneiras pelas quais as crianças podem ser entendidas como sujeitos participantes na sociedade. Nesse sentido, em contraposição à ideia de que crianças são somente atores passivos das estruturas e processos do mundo adulto, segundo a ideia durkheimiana de 
socialização, certos comportamentos contrários às regras parecem indicar outros caminhos para que sejam consideradas como parte da sociedade em que vivem, ou seja, a partir do lugar que nela ocupam, contribuindo para a produção e transformação da cultura (JAMES, 2014, p. 41).

A pesquisadora notou certa tolerância de alguns adultos, como a professora Cida, em relação ao descumprimento de regras por parte das crianças. Ela pareceu acreditar na necessidade de as crianças terem mais liberdade para correr no pátio, falar durante as refeições entre outras quebras de regras. Porém, para a maioria dos adultos, percebeu-se que, em suas relações com as crianças, havia pouca possibilidade de elas opinarem ou agirem com liberdade. Observou-se que, para os adultos, as crianças precisavam ser conduzidas, para seu próprio bem, no presente e no futuro. Era o adulto, como condutor desse processo, quem sabia o que era melhor: o que comer, como comer, como se expressar, como movimentar-se entre outros comportamentos.

Com relação ao comportamento das crianças observado na creche, o livre, o imprevisível, não era, portanto, visto como produtivo, pois poderia colocar em risco a ideia de bom comportamento esperado pelos adultos. Quando as crianças reagiam às regras de maneira diferente, a punição era certa e esperada, evidenciando uma punição também simbólica. O adulto chamava a atenção da criança, quando observava alguma quebra de regra. A criança era, portanto, repreendida por seu comportamento inadequado, por ser "passível de pena o campo indefinido do não-conforme" (FOUCAULT, 1986, p. 160). Por outro lado, o comportamento da criança era reforçado positivamente quando correspondia ao esperado pelo adulto.

Nakamura (2009) descreve os papéis da criança e do adulto, estabelecidos histórica, social e culturalmente, como associados aos diversos campos científicos, inclusive a educação. A definição desses papéis passa a regular o comportamento da criança pela perspectiva do adulto. A autora afirma que o modo como esses campos científicos intervêm nas crianças consideradas fora de uma normalidade esperada de infância revela "uma noção histórica e sociocultural de socialização caracterizada pela conformação dos comportamentos infantis ao mundo adulto, ao mesmo tempo que se define o lugar e o papel das crianças na sociedade mediante sua regulação físico-moral" (NAKAMURA, 2009, p. 259).

Nesse sentido, as concepções e práticas que norteiam o universo infantil na sociedade, articuladas aos diversos campos epistemológicos, são forjadas pelos adultos.

A criança quando transgride está se contrapondo a uma noção de infância normal, mas nem sempre isso significa que esteja confrontando o adulto, tratase somente de um modo de agir diferente.

O sociólogo Norbert Elias (2016, p. 470) argumenta que "descobrir as crianças significa, em última medida, dar conta da relativa autonomia, ou, em outras palavras, deve-se descobrir que elas não são simplesmente adultos pequenos". O autor tece considerações sobre as relações na contemporaneidade 
e as novas possibilidades no exercício dos papéis sociais. Os lugares ocupados na sociedade estão fluidificando, porém com tensões e contradições, e isso requer que o indivíduo assuma um maior controle sobre a própria vida.

A noção de processo civilizatório, apresentada pelo autor, tem levado ao debate sobre os conflitos gerados nesse processo, principalmente pela transição dos modelos interacionais entre adultos e crianças, como apontam Nakamura, Planche e Ehrenberg (2018). De acordo com os pesquisadores, a transformação de um modelo de socialização disciplinar não ocorre sem tensões, pois a autoridade do adulto tem que conviver com certa autonomia da criança, numa relação mais equitativa. Os autores apontam, assim, o desafio, nas sociedades contemporâneas, da manutenção simultânea da autoridade do adulto e da autonomia das crianças, em relações que envolvem não apenas os familiares e suas crianças, mas outros atores e instituições de maneira interdependente.

\section{Considerações finais}

O campo escolhido para a realização da pesquisa trouxe reflexões acerca da socialização das crianças, onde as regras, a disciplina e o processo da aprendizagem têm o objetivo na preparação da criança para o futuro. Observouse, de um lado, um processo de socialização em que a criança é vista enquanto "matéria prima" esculpida por meio da mediação do adulto. Por outro lado, no contexto pesquisado, a criança quando transgride as regras, quando não apresenta comportamento esperado, segundo padrões e regras social e culturalmente determinados, é vista como malcriada, mal-educada, ou seja, denotando falha na transmissão e assimilação da cultura compartilhada com adultos, com o risco de ter sua "vida real" ameaçada, sem futuro.

Portanto, nas situações analisadas no que se refere às regras, a criança parece ter vivenciado pouco exercício de seu protagonismo, dando a impressão que a infância fica relegada a uma preparação para a vida, vida essa que é sinônimo de ser adulto. A pesquisadora observou que, muitas vezes, esse é um processo naturalizado nas práticas, porque os adultos sentem-se responsáveis em passar as regras para as crianças com a expectativa de que sejam assimiladas e cumpridas. No entanto, em alguns momentos também foi observada a flexibilização dessas mesmas regras por parte do adulto, dependendo da criança e da situação. Por outro lado, também foram notadas situações de transgressão às regras pelas crianças, como descrito acima.

A flexibilização das regras pelos adultos e a sua transgressão pelas crianças são situações que, de acordo com Norbert Elias (2016), refletem um momento muito específico de transição, nas sociedades contemporâneas, no que diz respeito à indefinição dos papéis sociais do adulto e da criança, principalmente em relação à relativa autonomia das crianças e sua interdependência com adultos.

Ao contrário da perspectiva de socialização que atribui à criança um papel assimétrico, passivo, na relação com adultos, os dados da pesquisa parecem apontar para uma criança que opera de maneira criativa a comunicação 
relacionada às regras, elaborando e também produzindo cultura. Porém, como explica Cohn (2005), isso não quer dizer que haja uma autonomia absoluta por parte das crianças, pois a criatividade que se revela na comunicação entre elas é parte de um sistema de significados compartilhado com o mundo dos adultos. Nesse sentido, ao invés de assimetria, podemos pensar em relações mais simétricas entre crianças e adultos, no que se refere à comunicação entre eles.

Quanto à noção de socialização, a relação entre autonomia e disciplina tem seus significados transformados nas sociedades contemporâneas, principalmente pela ênfase dada ao conceito de autonomia nessas sociedades, parecendo deslocar-se de relações pautadas em modelos de autoridade para modelos mais igualitários e simétricos, como ressaltado por Cohn (2005). No entanto, longe de uma autonomia das crianças em relação aos adultos, o que a ideia de simetria nessa relação parece indicar é a possibilidade de afirmação da interdependência, tanto de adultos como de crianças, numa negociação complexa de expectativas, responsabilidades e comportamentos. Nesse sentido o protagonismo infantil não é sinônimo de autonomia absoluta, mas de reconhecimento da atuação das crianças no presente e da sua maneira peculiar de vivenciar a cultura, onde ela aprende e também ensina, transforma-se na interação com os adultos e seus pares, mas também é agente de transformação.

Espera-se com essas reflexões poder contribuir, de um lado, para o fomento de novas pesquisas com crianças e não apenas sobre elas, de outro lado, reorientar as formas de comunicação entre adultos e crianças não as restringindo a regras de adultos, mas reconhecendo o lugar das crianças, também como protagonistas e sujeitos nessa relação.

\section{REFERÊNCIAS}

ARIÈS, Philippe. História social da criança e da família. 2. ed. Rio de Janeiro: Zahar, 1981. 279p., $21 \mathrm{~cm}$. (Antropologia social).

COHN, Clarice. Antropologia da criança. Rio de Janeiro: Zahar, 2005. 58p., $18 \mathrm{~cm}$. (Ciências sociais passo-a-passo, v. 57). ISBN 8571108552 (broch.).

COHN, Clarice. Concepções de infância e infâncias: um estado da arte da antropologia da criança no Brasil. Civitas - Revista de Ciências Sociais, Porto Alegre, v. 13, n. 2, p. 221-244, 2014. Disponível em: https://doi.org/10.15448/1984-7289.2013.2.15478. Acesso em: 21 jul. 2021.

COHN, Clarice. Crianças Indígenas: introdução ao dossiê, estado da arte e agenda de pesquisas. Revista de @ntropologia da UFSCar, São Carlos, v. 11, n. 1, p. 10-34, 2019. Disponível em: http://www.rau.ufscar.br/wpcontent/uploads/2019/10/Apresentacao-1.pdf. Acesso em: 21 jul. 2021.

DURKHEIM, Émile. Educação e sociologia. São Paulo: Edipro, 2016. 94 p., $21 \mathrm{~cm}$. Inclui bibliografia. ISBN 9788572839716. 
ELIAS, Norbert. A civilização dos pais. Sociedade e Estado, Brasília, v. 27, n. 3, p. 469-493, 2016. Disponível em:

https://periodicos.unb.br/index.php/sociedade/article/view/5679. Acesso em: 21 jul. 2021.

FOUCAULT, Michel. Vigiar e punir: nascimento da prisão: história da violência nas prisões. 4. ed. Petrópolis, RJ: Vozes, 1986.

GEERTZ, Clifford. A interpretação das culturas. Rio de Janeiro: Guanabara Koogan, 1989.

JAMES, Alisson. Agency. In: QVORTRUP, Jeans; CORSARO, William A.; HONIG, Michael-Sebastien (ed.). The Palgrave Handbook of Childhood Studies. Palgrave Macmillan, 2014. p. 34-45.

JAMES, Allison; PROUT, Alan. Introduction. In: JAMES, Allison; PROUT, Alan. (ed.). Constructing and Reconstructing Childhood: contemporary issues in the sociological study of childhood. Routledge, 2015. p.1-6.

MARCHI, Rita Cassia. Pesquisa etnográfica com crianças: participação, voz e ética. Educação \& Realidade, Porto Alegre, v. 43, n. 2, p. 727-746, 2018. Disponível em: https://doi.org/10.1590/2175-623668737. Acesso em: 21 jul. 2021.

MÜLLER, Fernanda; NASCIMENTO, Maria Leticia Barros Pedroso. Apresentação. Linhas Críticas, Brasília, v. 20, n. 41, p. 11-22, 2014. Disponível em: https://doi.org/10.26512/lc.v20i41.4248. Acesso em: 21 jul. 2021.

NAKAMURA, Eunice. A noção médico-científica de depressão infantil: uma visão histórica e sociocultural do discurso de adultos sobre a infância. In: Mota, A., \& Schraiber, L. B. (eds.). Infância \& Saúde: perspectivas históricas. São Paulo: Hucitec, 2009. p. 234-264.

NAKAMURA, Eunice; PLANCHE, Maelle; Planche M., EHRENBERG, Alain. The social aspects in the identification of children's mental health problems in two health services in Paris, France. Interface: Comunicação, Saúde, Educação, v. 22, n. 65, p. 411-22, 2018. Disponível em: https://doi.org/10.1590/180757622016.0911. Acesso em: 21 jul. 2021.

PIRES, Flávia. Ser adulta e pesquisar crianças: explorando possibilidades metodológicas na pesquisa antropológica. Revista de Antropologia, São Paulo, v. 50, n. 1, p. 225-270, 2007. DOI: 10.1590/S0034-

77012007000100006. Disponível em:

https://www.revistas.usp.br/ra/article/view/27261. Acesso em: 21 jul. 2021. 
PIRES, Flávia. Pesquisando crianças e infância: abordagens teóricas para o estudo das (e com as) crianças. Cadernos de Campo, Araraquara, v. 17, n. 17, p. 133-151, 2008. DOI: 10.11606/issn.2316-9133.v17i17p133-151.

Disponível em:

https://www.revistas.usp.br/cadernosdecampo/article/view/47058. Acesso em: 21 jul. 2021.

PIRES, Flávia. O que as crianças podem fazer pela antropologia? Horizontes Antropológicos, Porto Alegre, v. 16, n. 34, p. 137-157, 2010. Disponível em: https://doi.org/10.1590/S0104-71832010000200007. Acesso em: 21 jul. 2021.

PROUT, Alan. Taking a Step Away from Modernity: Reconsidering the New Sociology of Childhood. Global Studies of Childhood, v. 1, n. 1, p. 4-14, 2011. Disponível em:

https://journals.sagepub.com/doi/pdf/10.2304/gsch.2011.1.1.4. Acesso em: 21 jul. 2021.

SARMENTO, Manuel Jacinto. Gerações e alteridade: interrogações a partir da sociologia da infância. Educação \& Sociedade, Campinas, v. 26, n. 91, p. 361-378, 2005. Disponível em: https://doi.org/10.1590/S010173302005000200003. Acesso em: 21 jul. 2021.

SARMENTO, Manuel Jacinto. Sociologia da infância: correntes e confluências. In: SARMENTO, Manuel Jacinto; GOUVEA, Maria Cristina Soares de. (ed.). Estudos da infância: educação e práticas sociais. Petrópolis, RJ: Vozes, 2008. 277p., il., 23 cm. p. 17-39. (Ciências sociais da educação). Inclui bibliografia. ISBN 9788532637161 (broch.). 